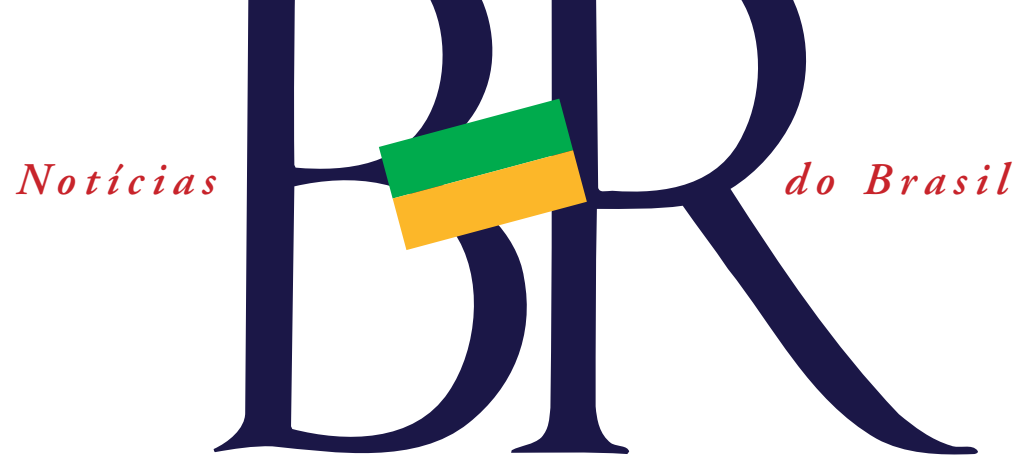

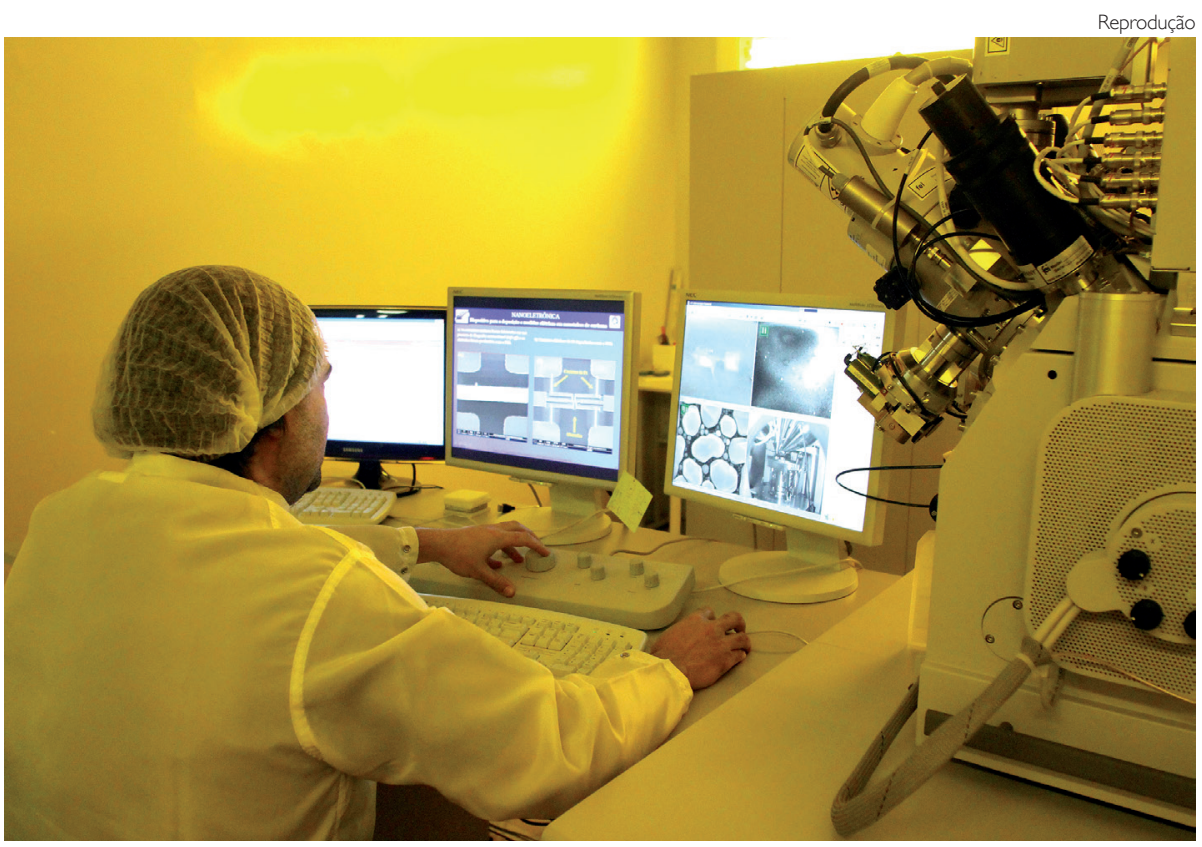

Exames ainda lidam com margem de incerteza. Este é o caso da mamografia. Cerca de $25 \%$ das que indicam presença de câncer não definem se paciente desenvolverá doença

SAÚDE

\section{Excesso de exames para detecção de doenças pode gerar diagnósticos prematuros e ações desnecessárias}

Na maioria dos dicionários o significado de diagnóstico é: qualificação dada por um médico a uma enfermidade ou estado fisiológico, com base na observação de sintomas e de exames diversos. A relação médico-paciente, porém, não é simples, e vai além de meramente avaliar o quadro clínico e tratar a doença detectada. A proliferação de testes diagnósticos sofisticados, frutos de descobertas médicas e no- vas tecnologias, permite maior precisão e antecedência na detecção de enfermidades o que, porém, pode gerar excessivas e invasivas condutas médicas, e até conduzir à prescrição de tratamentos desnecessários. Isso ocorre seja nas doenças graves, como cânceres ou autoimunes, assim como transtornos psíquicos e síndromes genéticas.

O caso do câncer é um bom exemplo, diz Gustavo Cardoso Guima- rães, diretor do serviço de urologia do hospital A.C. Camargo de São Paulo, um dos hospitais mais conceituados do país para tratamento de câncer. Ele relata que muitas vezes apesar do paciente receber diagnóstico de câncer de próstata, pode ser que nunca desenvolva de fato a doença. Atualmente rastreia-se o tumor prostático (um dos mais frequentes na população mundial masculina) por meio da proteína sanguínea PSA e, caso os níveis estejam elevados, o paciente é encaminhado para realização de biópsia, único método confirmatório. "Mesmo o paciente tendo resultados positivos em ambos os testes, não se consegue antever o que acontecerá”, esclarece. Para o urologista, "apesar de termos a capacidade de diagnosticar a maioria dos pacientes com tumores da próstata, ainda não estamos aptos a distinguir totalmente os pacientes nos quais a doença evolui, tornando-se um grave problema de saúde, daqueles que têm a doença e mesmo assim não apresentam sintomas ou qualquer problema".

O câncer de mama feminino é outro que engorda os números dessa espinhosa antevisão diagnóstica. De acordo com Daniel Guimarães Tiezzi, docente e médico do setor mastologia e oncologia ginecológica da Faculdade de Medicina de Ribeirão Preto (FMRP) da USP, "por meio da mamografia, pode- 
Noticias

mos diagnosticar lesóes que podem ou não evoluir para um câncer mais agressivo, bem como diagnosticar lesões altamente invasivas, mas que nunca iriam progredir, ou progrediriam tão lentamente que acabariam não interferindo na qualidade de vida atual ou futura dessas pacientes". Estudo recente da Universidade de Harvard (Estados Unidos), estimou que $15 \%$ a $25 \%$ de todos os casos de carcinoma de mama diagnosticados durante o rastreamento não necessitariam de tratamento. No trabalho, foi calculado que "a cada 2500 mulheres, 6 a 10 seriam tratadas desnecessariamente; 20 receberiam o tratamento adequado, enquanto apenas umamorte pela doença seria prevenida", analisa Tiezzi.

A essas falhas de discriminação entre os que serão dos que não serão afetados por uma doença apesar do diagnóstico favorável, atribui-se o nome de sobre-diagnóstico (ou overdiagnosis), que, segundo Tiezzi, "sempre irá existir, com maior ou menor frequência, quando estamos falando de rastreamento de câncer". Uma revisão sobre o assunto ("Cancer overdiagnosis and overtreatment") estampou as folhas da revista Current Opinion in Urology em maio deste ano. Nelas, Laurence Klotz, chefe da divisão de urologia do Centro de Ciências da Saúde Sunnybrook em Toronto, Canadá, descreve que o sobre-diagnóstico tem se tornado um dos maiores problemas atuais da medicina: "houve aumento considerável de diagnósticos clinicamente insignificantes". Entretanto, ao menos no câncer de próstata, isso não é nada ruim, uma vez que "o rastreamento (...) reduz significantemente a mortalidade [dos pacientes]", conclui o autor.

\section{BUSCANDO NOVOS HORIZONTES GUi-} marães comenta que um dos problemas de se rastrear o câncer de próstata é que o PSA elevado (exame padrão) não indica necessariamente alteração tumoral desse órgão. "O aumento do PSA no sangue pode ser encontrado após um trauma (choque ou fricção) ou depois da relação sexual", ensina. Buscando melhorias na especificidade do exame, em agosto de 2011, a revista científica Science Translational Medicine, publicou um estudo ("Urine TMPRSS2:ERG fusion transcript stratifies prostate cancer risk in men with elevated serum PSA") descrevendo um exame mais acurado, que chamou a atenção de oncologistas para o poder de discriminação quanto à presença de câncer prostático. Porém os resultados devem ser interpretados cautelosamente. "O número de pessoas em que isso foi testado, assim como a etnia dessas pessoas, precisam ser levados em conta; e isso é importante em qualquer pesquisa desse tipo", avisa o médico, lembrando que o câncer de próstata é mais agressivo em negros.

PRECAuÇão O hospital A.C. Camargo lançou campanha publicitária este ano para mobilização pelo diagnóstico do câncer em estágio inicial. Com isso, tenta-se curar o paciente dos cânceres de maior incidência no país (pele, próstata, mama e intestino), que "alcançam hoje $90 \%$ de sucesso no tratamento quando diagnosticados precocemente", segundo a instituição. Contudo, enquanto tratamentos eficientes não são realidade para todos os tipos de câncer, outros métodos, ainda que hostis, parecem ser a saída para cura. Guimarães relata que quando há antecedentes familiares de câncer, "pode haver indicação de retirada do órgão por precaução, como são os casos do câncer de tireóide e colorretal (que afeta parte do intestino grosso e o reto)". Tiezzi relata que "algumas pacientes tem um risco alto, de 50 a 60\%, de desenvolver câncer mamário, e a cirurgia de retirada das mamas de forma preventiva pode reduzir o risco em 90\%".

O RISCO É REAL? "O risco de desenvolvimento de câncer de mama, por causa de mutações no DNA, em específico nos genes BRCA1 e BRCA2, pode variar de 37 a $87 \%$ ao longo da vida", declara Anto- 
Noticias

ficas". Ainda por cima parece que "há uma tendência de a imprensa focar-se em pontos polêmicos, como a real existência do TDAH, passando mensagens nada informativas para as pessoas que não conhecem bem o transtorno" arremata Polanczyk.

NA SAÚdE E NA DOEnÇA Para agravar essa inconsistência médica, nem todos os pedidos de exames são feitos dentro dos parâmetros da ética e do foco exclusivo no paciente. "Alguns exames são mesmo solicitados a torto e a direito", exclama Ciro Dresch Martinhago, médico geneticista e diretor do laboratório RDO Diagnósticos Médicos, ao mencionar testes genéticos que investigam praticamente todos os cromossomos do embriáo, nos casos de fertilização in vitro feita em clínicas de reprodução assistida. Para ele o grande vilão da história é a falta de critério para requisição desses métodos. Ao mesmo tempo admirador das tecnologias de ponta que podem fornecer resultados mais seguros e efetivos, Martinhago é cauteloso: "em todas as situações é preciso haver indicação para se pedir qualquer tipo de exame". Ele assegura que o próximo passo do exame pré-natal é tornar rotineiro o teste que identifica Síndrome de Down por meio de análise de células fetais no sangue da gestante. Entretanto, "o médi- co não pode deixar-se guiar por modismos, já que muitos pedem exames modernos sem mesmo ter conhecimento da aplicação deles", garante Leila Montenegro Silveira Farah, doutora em biologia celular e molecular, experiente em diagnóstico pré-natal.

Com base nas experiências do dia a dia dos consultórios e hospitais, Ivan Savioli Ferraz, pediatra docente da FMRP, especula que "apenas menos de $20 \%$ das consultas precisariam gerar solicitação de exames". Para ele, esse excesso de pedidos se dá por conta de vários fatores, como a má formação médica, levando o recém-formado a inseguranças, que podem ser afastadas quando se mune de grande quantidade de exames. Ele aponta também que existe uma questão mercadológica nisso. "Alguns colegas costumam reduzir o tempo das consultas para aumentarem a renda, e acabam solicitando mais exames que o normal para avaliarem o estado completo do paciente". E vai além, "muitas vezes as pessoas chegam a acreditar que pedindo mais exames, o médico é mais íntegro por cuidar melhor de seus pacientes". Faz, porém, uma ressalva: no caso de doenças mais complexas, como o câncer, "os médicos têm que se cercar de todos os recursos disponíveis".

Daniel Blasioli Dentillo

\section{SAÚDE}

Crescimento de cirurgias plásticas demonstra fusão dos conceitos de saúde e beleza

Os padrões de aferição da beleza do corpo humano estão inscritos na cultura e são influenciados por fatores que estão além de sua materialidade. Ele é apenas um suporte desses valores produzidos pela ética, religião, política, enfim, pela cultura. A artista plástica francesa Orlan utiliza o próprio corpo em performances onde, por meio de cirurgias plásticas, ela faz modificações radicais em sua aparência. Olhos, lábios e até a colocação de chifres foram algumas dessas mudanças. Se isso não fosse o bastante, ela faz questão de que as intervenções cirúrgicas sejam documentadas e transmitidas, em alguns casos, ao vivo, para galerias, museus, como em um espetáculo. Orlan eleva ao máximo as possibilidades de modificação e exposição corporal. Para ela, o corpo é um lugar de debate público, onde se colocam questões cruciais de nossa época e a metamorfose corporal é uma delas. Dentre tantas possibilidades de operar essa metamorfose, a cirurgia plástica, um dos métodos mais radicais e rápidos, só cresce. 